\title{
National differences in materialism - Using alternative research strategies to explore the construct
}

\author{
Rudolf R. Sinkovics • Hartmut H. Holzmüller
}

\section{This is a pre-print (non-publisher's document). Please cite the published article:}

Sinkovics, Rudolf R. and Hartmut H. Holzmüller (2001), "National differences in materialism - using alternative research strategies to explore the construct," Journal of International Consumer Marketing, 13 (2), 103-134. (DOI: 10.1300/J046v13n02_06).

\section{Executive summary}

- Materialism is an important concept in tracking the value systems of individual consumers. It can serve both as a means of describing their material needs and desires, and as a proxy-variable for work on societal or cultural comparisons. The knowledge and assessment of differences in materialism can be useful for marketing managers who continuously attempt to satisfy customer needs through a coordinated set of marketingactivities. The knowledge of materialism scores can, for instance, influence the success of advertising, decisions on product positioning and the selection of distribution channels. Furthermore, materialism can play a vital part in the segmentation and targeting process. Within a more general framework, materialism scores can provide insight into national idiosyncrasies and the conceptual underpinnings of these differences. Materialism is therefore an important instrument in the enrichment of international marketing and crossnational marketing research.

- However, when thinking about cross-national marketing research and the practical issues involved, the most crucial aspect is to establish results which are comparable across those national entities involved. Clearly we can see that idiosyncratic features of countries and consumers, differences in attitudes, as well as distinctive patterns of sociocultural behavior and values limit the cross-national comparability of results. Two different schools of thought have been introduced in the literature, the 'emic' and 'etic' schools of thought, which both try to tackle the comparability challenge from a different angle. They represent two extremes on the continuum of cross-national research methodology, where 'emic' research typically rests on qualitative techniques, while 'etic' research is usually grounded on quantitative techniques.

- Within this article, a combination of alternative, qualitative and quantitative research strategies was used to explore national differences in materialism. From a methodological point of view, the findings call for the use of 'alternative research strategies' to overcome the emic - etic duality in cross-national research. While this approach does not necessarily make the 'incomparable' comparable, it helps to find out about the reasons for incomparability.

- In the context of our materialism-study, the application of formalized qualitative steps of data coding and interpretation helped to understand why the 'materialism' concept is 'culture-bound' and why the same way of measuring across the nations did not provide satisfactory results. A graphical representation of the mindset of respondents helped to 
explore the reasons for the conceptual differences.

\section{Abstract}

- One of the core objectives in cross-national marketing research is to establish research results which are comparable across national entities. Nevertheless certain national idiosyncrasies (unique meaning of constructs, distinctive expressions) may hamper these cross-national research endeavors. Two different approaches have been introduced in the social sciences, in order to cope with this comparability-dilemma. The "emic" and the "etic" school of thought. These can be seen as two extremes on the continuum of crossnational research methodology.

- The paper tries to illustrate advantages and potential shortcomings of the etic (mostly quantitative) vs. the emic (mostly qualitative) research approach. A combination of alternative, qualitative and quantitative research strategies was used to explore national differences in materialism. A questionnaire was developed comprising both both qualitative and quantitative sections on materialism. The materialism scale, as operationalized by Richins and Dawson (1992) was used, for the quantitative section. The research findings call for the use of 'alternative research strategies' to overcome the emic - etic duality in cross-national research. Comparative text analysis and graphical representations of consumers statements can help to explore the reasons for conceptual differences.

\section{Key words}

Emic-etic research, Materialism, Formalized qualitative research, comparative text-analysis, consumer values

\section{Authors}

Rudolf R. Sinkovics $(\bowtie)$

Manchester Business School, UK

(e-mail: Rudolf.Sinkovics@manchester.ac.uk)

Hartmut H. Holzmüller

University of Dortmund

(e-mail: hartmut.holzmueller@udo.edu)

\section{This is a pre-print (non-publisher's document). Please cite the published article:}

Sinkovics, Rudolf R. and Hartmut H. Holzmüller (2001), "National differences in materialism - using alternative research strategies to explore the construct," Journal of International Consumer Marketing, 13 (2), 103-134. (DOI: 10.1300/J046v13n02_06). 


\section{National Differences in Materialism - USing Alternative Research} STrategies TO EXPLORE THE CONSTRUCT

\section{INTRODUCTION}

The marketing concept can be defined as an organization's attempts to satisfy customer needs through a coordinated set of activities. Marketers are therefore engaged in an examination of what drives consumers, what "good living" means across various consumer segments and how best to cater for the well-being of the consumer.

Materialism is clearly an important concept in tracking the value systems of individual consumers. It can serve both as a means of describing their material needs and desires, and as a proxy-variable for work on societal or cultural comparisons. Knowledge and assessment of differences in materialism can be useful for practical marketing programs. Materialism scores can, for instance, influence the success of advertising, decisions on product positioning and the selection of distribution channels. Materialism can also play a part in the segmentation and targeting process. Within a more general framework, materialism scores can provide insight into national idiosyncrasies and the conceptual underpinnings of these differences. Materialism is therefore an important instrument in the enrichment of international marketing and cross-national marketing research.

From a managerial perspective, the most crucial aspect of cross-national marketing research is the establishment of results which are comparable across the entities under study. However, idiosyncratic features of countries and consumers, differences in attitudes, as well as distinctive patterns of sociocultural behavior and values limit the cross-national comparability of results. The 'emic' and 'etic' schools of thought, which have been introduced in the literature to cope with the challenges of comparing attitudinal and behavioral phenomena, represent two extremes on the continuum of cross-national research methodology.

Typically, quantitative methods are used in cross-national 'etic' research, which is concerned with the identification and assessment of universal attitudinal and behavioral concepts and the development of 'culture-free' measures. The 'emic' school of thought states that attitudinal and behavioral phenomena are unique to a culture, and best understood on their own terms. Emic research typically rests on qualitative techniques, measures which were adapted in each country under investigation, and judgmental comparisons in a qualitative manner.

This article uses a combination of alternative, qualitative and quantitative research strategies to explore national differences in materialism. The notion of materialism will be elaborated upon, previous attempts to measure the construct will be reviewed and exploratory findings on a quantitative and qualitative materialism study will be reported.

\section{CONCEPTUAL BACKGROUND}

\subsection{Materialism and International Marketing}

Domestic and international economic growth patterns are a major force for structural change in our world. Our socio-economic reality is continuously and rapidly updated and as a consequence the concept of materialism has become of great interest to those in marketing and consumer research (Belk 1985; Muncy and Eastman 1998; Richins and Dawson 1992).

\footnotetext{
* The authors would like to thank Dr. Saeed Samiee, University of Tulsa, OK, for his help in the data collection process
} 
Consumers are "yearn(ing) to acquire and consume" (Cushman 1990, p. 600) and are engaged in "a ceaseless pursuit of the "good life" (Fox and Lears 1983, p. xii). These arguments demonstrate the topicality of the concept and express different views of materialism. On the one hand materialism may increase a society's economic wealth and material possessions, while on the other hand, materialism may have a negative overall effect on quality of life (La Barbera and Zeynep 1997), lower ethical standards of consumers (Kwon et al. 1999) or harm the environment (Feldman 1971; Muncy and Eastman 1998).

The terms "materialism" and "materialistic" are often used freely and interchangeably without definition. Materialism refers to a "devotion to material needs and desires, to the neglect of spiritual matters; a way of life, opinion, or tendency based entirely upon material interests" (Oxford English Dictionary). Belk (1984, p. 291) defines materialism as "the importance a consumer attaches to worldly possessions. At the highest levels of materialism, such possessions assume a central place in a person's life and are believed to provide the greatest sources of satisfaction and dissatisfaction".

The study of materialism is cross-disciplinary (Lundstrom and White 1999) and Belk's work certainly stimulated some follow-up work in the marketing domain (Mukerji 1983; Rassuli and Hollander 1986). With the exception of Belk's (1984) work, none of the materialism measures involved the application of commonly accepted standards for scale development (Churchill 1979; Nunnally 1978). However, a limitation of Belk's scale relates to inconsistent reports of scale reliability, often with low alpha-levels. Furthermore, looking at the number of publications on materialism and related topics (see Table 1 below), it appears that the synergizing work of Richins and Dawson (1992) has found a broader acceptance among researchers.

Table 1: Measures of Materialism reported in earlier studies

\begin{tabular}{|c|l|}
\hline I. Measures of materialism reported in Richins and Dawson's work (1992, p. 306) \\
\hline I.a. Measures that infer materialism from related constructs \\
\hline $\begin{array}{l}\text { Dickins and Ferguson } \\
\text { (1957) }\end{array}$ & $\begin{array}{l}\text { Content analysis of responses to five open-ended questions: } \\
\text {,If you could make three wishes and they would all come } \\
\text { true, what would you wish for?" }\end{array}$ \\
\hline Justice and Birkman (1972) & $\begin{array}{l}\text { Subscale of the Birkman vocational interest and attitude } \\
\text { survey; materialism inferred from true-false questions } \\
\text { concerning social perceptions and self-image }\end{array}$ \\
\hline $\begin{array}{l}\text { Bengston and Lovejoy } \\
\text { (1973) }\end{array}$ & $\begin{array}{l}\text { Materialism/humanism factor scores based on rankings of 16 } \\
\text { values: "finances", "possessions", "service" }\end{array}$ \\
\hline Burdsal (1975) & $\begin{array}{l}\text { Materialistic motivations inferred from factor scores on } \\
\text { Cattell's motivational analysis test }\end{array}$ \\
\hline $\begin{array}{l}\text { Jackson, Sadrudin, and } \\
\text { Heapy (1976) }\end{array}$ & $\begin{array}{l}\text { Acquisitiveness subscale of the six-dimensional achievement } \\
\text { scale; includes Likert scale, semantic differential, and } \\
\text { adjective checklist items }\end{array}$ \\
\hline Inglehart (1981) & $\begin{array}{l}\text { Materialist and postmaterialist goals; 12 goals ranked by } \\
\text { importance: "maintain a stable economy", "try to make our } \\
\text { cities and countryside more beautiful" }\end{array}$ \\
\hline Belk (1984) & $\begin{array}{l}\text { Personality traits of envy, nongenerosity, and } \\
\text { possessiveness; 24 Likert scale items: "I am bothered when I } \\
\text { see people who buy anything they want", "I don't like to } \\
\text { lend things, even to good friends", "I tend to hang on to } \\
\text { things I should probably throw out" }\end{array}$ \\
\hline I.b. Attitude measures of materialism: \\
\hline Campbell (1969) & \begin{tabular}{l} 
Materialism; eight items, forced-choice format: "If things \\
\hline
\end{tabular}
\end{tabular}




\begin{tabular}{|c|c|}
\hline & $\begin{array}{l}\text { were such that everybody in the world had stereophonic } \\
\text { record players and champagne, wars would probably be } \\
\text { obsolete" }\end{array}$ \\
\hline $\begin{array}{l}\text { Wackman, Reale, and Ward } \\
\text { (1972) }\end{array}$ & $\begin{array}{l}\text { Materialism; } 5 \text { items, Likert scale format: "It's really true } \\
\text { that money can buy happiness" }\end{array}$ \\
\hline $\begin{array}{l}\text { Moschis and Churchill } \\
\text { (1978) }\end{array}$ & Materialism; 6 items, adaptation of Wackman et al. (1972) \\
\hline De Young (1985) & $\begin{array}{l}\text { Nonmaterialism; six items, two subscales, Likert scale } \\
\text { format: "It is important to me to have really nice things" }\end{array}$ \\
\hline Richins (1987) & $\begin{array}{l}\text { Materialism; six items, two subscales, Likert scale format: } \\
\text { "It is important to me to have really nice things" }\end{array}$ \\
\hline $\begin{array}{l}\text { Henslin, Johnson, and Blake } \\
\text { (1989) }\end{array}$ & $\begin{array}{l}\text { Materialism; subscale of the spender scales; six items, Likert } \\
\text { scale format }\end{array}$ \\
\hline \multicolumn{2}{|c|}{ II. Studies on materialism and related constructs, published after Richins and Dawson (1992) } \\
\hline Richins (1994) & $\begin{array}{l}\text { Materialism; Richins and Dawson (1992) measure, } \\
\text { Assessment of the extent to which the possessions express } \\
\text { the owners' material values }\end{array}$ \\
\hline Richins and Rudmin (1994) & $\begin{array}{l}\text { Materialism; Richins and Dawson (1992) items; connection } \\
\text { between materialism and economic psychology. Description } \\
\text { of individual's real and desired relationship with economic } \\
\text { goods }\end{array}$ \\
\hline Dittmar and Pepper (1994) & $\begin{array}{l}\text { Materialism; Richins and Dawson (1992) measure; } \\
\text { investigation of how materialism affects the way in which } \\
\text { adolescents from different social class backgrounds perceive } \\
\text { a person who is portrayed as either owning or lacking } \\
\text { expensive possessions }\end{array}$ \\
\hline Zinkhan (Zinkhan 1994) & Conceptual paper on terminal vs. instrumental materialism \\
\hline $\begin{array}{l}\text { Claxton, Murray and } \\
\text { Swinder (1995) }\end{array}$ & $\begin{array}{l}\text { Materialism; measured by subscales adapted from Belk's } \\
\text { materialism subscales "possessiveness", "nongenerosity" and } \\
\text { "envy" (1984) }\end{array}$ \\
\hline $\begin{array}{l}\text { Mannion and Brannick } \\
\text { (1995) }\end{array}$ & $\begin{array}{l}\text { Conceptual paper on materialism, its measurement and its } \\
\text { contribution to consumer research }\end{array}$ \\
\hline Ger and Belk (1996) & $\begin{array}{l}\text { Materialism; measures of consumer desires, perceived } \\
\text { necessities and adapted versions of the Belk (1985) scale }\end{array}$ \\
\hline La Barbera (1997) & $\begin{array}{l}\text { Materialism; Richins and Dawson measure and own } \\
\text { adaptations. Investigation into consumer subjective well- } \\
\text { being and its relationship to selected secular and sacred } \\
\text { values }\end{array}$ \\
\hline $\begin{array}{l}\text { Eastman, Fredenberger, } \\
\text { Campbell and Calvert } \\
\text { (1997) }\end{array}$ & $\begin{array}{l}\text { Materialism; measured by Richins and Dawson (1992) } \\
\text { items. Comparison of individual difference levels among } \\
\text { college students from three countries }\end{array}$ \\
\hline $\begin{array}{l}\text { Lundstrom and White } \\
\text { (1999) }\end{array}$ & $\begin{array}{l}\text { Materialism; measured as possession satisfaction (PS), } \\
\text { developed by Scott and Lundstrom (1990). PS scale is } \\
\text { measure of values, thus in line with Richins and Dawson's } \\
\text { (1992) view of materialism. Empirical investigation into } \\
\text { France-US differences }\end{array}$ \\
\hline Muncy and Eastman (1998) & $\begin{array}{l}\text { Materialism; Richins and Dawson (1992) } \\
\text { operationalizations. Investigation of the relationship between } \\
\text { materialism and consumer ethics }\end{array}$ \\
\hline
\end{tabular}


In 7 out of 10 studies $^{1}$, researchers relied on the Richins and Dawson operationalization of materialism for their own work. According to Richins and Dawson (1992, p. 308) materialism can be thought of as a value, which is "a set of centrally held beliefs about the importance of possessions in one's life" and can be measured in the three belief domains: "acquisition centrality", "acquisition as the pursuit of happiness" and "possession-defined success".

- Acquisition Centrality. Materialists place possessions and their acquisition at the center of their lives. Materialism brings meaning to life and provides an aim for daily endeavors (Bredemeier and Toby 1960). For some materialists "consumption for the sake of consumption becomes a fever that consumes all the potential energy it can get access to" (Csikszentmihalyi and Rochberg-Halton 1981).

- Acquisition as the pursuit of happiness. According to Belk (Belk 1984) the reasons that possessions and their acquisition are so central to materialists is that they view these as essential to their satisfaction and well being in life. Materialism is "an orientation emphasizing possessions and money for personal happiness and social progress" (Ward and Wackman 1971)

- Possession-defined Success. The number and quality of possessions accumulated is a basis for judgement of the materialists own and others' success (Richins and Dawson 1992). According to Heilbroner's analysis, acquisitive, materialistic people value possessions "for the money they cost rather than by the satisfactions they yield" (Heilbroner 1956).

Given the broad use of Richins and Dawson's work, we decided to build our research on their conceptualization. As reported in Table 1, there are only a limited number of studies on a cross-national replication and validation of materialism (either Belk's or Richins and Dawson's approach). From a cross-cultural or cross-national perspective none of the published articles has dealt with the conceptualization per se. In this sense, national differences have been reported without questioning whether the underlying construct was appropriate. This is why we chose to use a 'mixed methods' approach for exploring national differences in materialism. Using qualitative as well as quantitative techniques we elaborated on the construct and tried to identify potential national differences in materialism. The following chapter will devote some space to the discussion of cross-national research and measurement issues.

\subsection{Cross-national marketing research}

The selection of research strategies in cross-national marketing research is determined by two aspects. Firstly, researchers have to consider the level of existing knowledge in the field of research. In some situations the available expertise is very limited, little or no research has been done in that area and the underlying problems are ill-defined. Therefore it is necessary to use an open and flexible research design, which allows many constructs or facets to be covered during data collection, even those facets that were not expected or anticipated by the scholars in the conceptual phase. Exploratory research in new markets or on phenomena where no prior research has been conducted is a typical example of this situation. On the other hand research effort might focus on well documented areas, where a lot of knowledge is already available and the core objective is to obtain more detailed or up-to-date insights.

Secondly, it is of importance to clarify whether it is more important to generate cross-national data and findings which are comparable or whether the primary goal is the quality of

1 The publications selected represent the results of a search process of the term "materialism" in the top journals in marketing, consumer behavior and psychology. 
measurement in the specific countries under investigation. In other words, scholars have to decide on the position they take on the 'emic/etic'-continuum (Pike 1966) in accordance with the research questions. Researchers have to accept that there is a certain trade-off between the two schools of thought. If the focus of a cross-national research project is on a high level of comparability or the development of so called 'culture-free' measures (Elder 1976), it is appropriate to use data collection and analysis methods which are quantitatively more sophisticated or analytically challenging. These situations can be found where there is a necessity for high-speed implementation of the results in international decision making. However, for projects which aim to investigate phenomena more thoroughly and in detail it is important to emphasize measurement accuracy and it is advisable to use qualitative or interpretative research methods.

Looking at the situation from a typological perspective, the combination of the two different dimensions of research determinants leads to four different research strategies in crossnational marketing research (see Figure 1). The cells Type 1 and Type 4 represent congruent types which we can identify as quantitative and qualitative research methodologies respectively. They are congruent in the sense that with Type 1, an ill-defined problem requires qualitative methodology; with Type 4, well-defined problems are usually best researched by quantitative methodologies. Type 2 and Type 3 are mixed types. While the structure of the problem under scrutiny requires predominantly quantitative or qualitative methodologies, the integration of alternative research strategies may help to enhance interpretation and analysis. Obviously, Type 2 and Type 3 cannot completely be regarded as indicative of combinations of qualitative or quantitative research.

In this sense, Type 1 is exploratory research where qualitative methods are used to gain first insights into problems to be studied and into differences as compared with the domestic market. The research field is ill-defined and therefore the design has to be as open and as flexible as possible. Studies of this type can be used to pinpoint relevant aspects of the problem to be examined, and to identify and define appropriate concepts and constructs. Typical methods used in that context are observational techniques, field protocols and indepth interviews.

Figure 1: Typology of cross-national marketing research

\begin{tabular}{|c|c|c|c|}
\cline { 3 - 4 } \multicolumn{2}{c|}{} & \multicolumn{2}{c|}{ Methodology } \\
\cline { 3 - 4 } \multicolumn{1}{c|}{$\begin{array}{c}\text { Level of } \\
\text { knowledge }\end{array}$} & $\begin{array}{c}\text { ill-defined } \\
\text { problems }\end{array}$ & qualitative & quantitative \\
\cline { 2 - 4 } & $\begin{array}{c}\text { Type 1 } \\
\text { well-defined } \\
\text { problems }\end{array}$ & Type 3 & Type 4 \\
\hline
\end{tabular}

Research strategies that correspond to type 2 are also focused on less well-defined problems, where few or no prior research results are available. As there is a need for a high level of cross-national comparability it is necessary to use quantitative methods for this kind of explorative research. Survey research that includes a broad variety of variables and constructs is used to collect data, which in the next step is analyzed by exploratory structural equation modeling ('soft modeling' after Wold 1980; 1982). This technique allows the development of explanatory models in a dialog with empirical data. Results of this kind are exploratory and possible next steps include cross-validation on new samples of respondents. In addition to surveys certain types of quasi-observational techniques could also be used for data collection. 
Type 3 strategies can be applied to problems in a field of interest where insights have been discovered prior to the ongoing study. In order to obtain a deeper understanding of the phenomena under investigation, the researcher will focus on a selection of variables or constructs. For instance, prior research-findings might indicate that rather than focusing on cross-national comparisons, the emphasis should be placed on measurement accuracy in each national field. Thus qualitative data collection and interpretation techniques can be applied to gain new insights into the topic. Protocols, projective techniques, and free associations are typical means of data collection.

The final type of research strategy (Type 4) is the most common in international marketing research. In situations where a solid knowledge-base is available prior to the actual research process, quantitative methods are used to investigate phenomena. A core concern in these situations is to generate findings that are comparable across borders. In-depth coverage of the measures used is usually of less concern, because this has largely been done in earlier studies. Survey methods, often combined with psychographic measures, are used in data collection. Bi- and multivariate statistical methods are used in data analysis and interpretation.

Each type of research strategy described in Figure 1 has its specific advantages and limitations (in order to reduce complexity we focus on research strategies that aim at welldefined problems, i.e. Type 3 and 4). There is always a certain trade-off between measurement accuracy and comparability as well as exploratory and confirmatory research results. Qualitative strategies allow for a much better coverage of the variables or constructs under investigation and lead to a higher measurement accuracy compared to quantitative methods. On the other hand, the cross-national comparability is less meaningful and analytical techniques can only be used in the context of quantitative research.

Methodologically, there are basically two ways of bridging this research-dilemma and combining multiple methods in the research process (for a more comprehensive discussion see 1992; Bryman 1988):

- Integration of qualitative and quantitative approaches and the logic of 'triangulation': The findings from one type of study can be checked against the findings which were derived from another type. This does not merely involve methods and data but investigators and theories as well (Denzin 1970, p.310). Depending on whether there is a pre-eminence of the quantitative over the qualitative or a pre-eminence of the qualitative over the quantitative, background information on context and subjects may be used as a valuable source of hypotheses and aid scale construction at a later stage of the research process. Usually, for cross-national studies on marketing concepts and constructs, the use of qualitative methods is the first step within a data collection process which allows for more formalized analyses at a later stage of investigation (Miles and Huberman 1997). The results of a qualitative investigation might be checked against a quantitative study and vice versa. The purpose of this approach is generally to enhance the validity of the research findings. Therefore better cross-national comparisons and meaningful insights based on rich datasets can be derived by following this approach.

- Complementary combination of quantitative and qualitative strategies. This research avenue may be employed to fill in the gaps in a qualitative study which can arise because the researcher cannot be in more than one place at one time (Bryman 1992). Furthermore, issues which cannot be resolved by relying on either quantitative investigation or qualitative analysis alone can be explored. The quantitative and qualitative are given equal weight. "Combined methods may result in two separate but linked studies which are distinct from one another at all stages of the research process. Each study may have a life of its own from the design stage onwards. Alternatively, the methods are integrated in the one study, with the linkage occurring in the fieldwork phase or in the analysis or writing- 
up stage" (Brannen 1992). Studies under this heading may be conducted simultaneously or consecutively.

A combination of qualitative and quantitative approaches was used to explore national differences in materialism. While we did not attempt to compare the two methodological approaches according to their appropriateness for cross-national research, we tried to evaluate the contribution of the alternative research strategies to the common understanding of the materialism construct. First we used a questionnaire to measure materialism in different countries. The questionnaire was developed according to psychometric techniques and the findings were analyzed with multivariate statistical methods. Secondly we asked respondents an open-ended question to elicit their basic beliefs about important things in life. We used a qualitative technique, namely formalized and comparative text analysis for the interpretation of the results. The following chapter will devote some space to a conceptual discussion of formalized, comparative text analysis which will subsequently help us in the interpretation of our findings.

\subsection{Formalized, comparative text analysis}

Traditionally cross-national marketing research has been dominated by the use of quantitative methods: while textual data is a rich source of information which can help to interpret and describe social behavior, structures, values or norms, formalized and comparative text analysis is underrepresented in cross-national marketing research.

Textual data consists of "any text which constitutes a relevant and necessary source material for answering the questions one is interested in" (Melina 1998). Specific kinds of textual data can be: open responses to questionnaires, newspaper editorials, commentaries, titles, articles, different kinds of reports, e.g. company annual reports, memos, newspaper reports, etc.

There are an extraordinary large number of approaches to the formalized, comparative analysis of text data (Melina 1998): content analysis (Früh 1991; Weber 1990), concordance analysis (Ellis 1968), conversational analysis (Sacks 1972), computational hermeneutics (Mallery 1985), qualitative text analysis (Kelle 1995; Weitzman and Miles 1995), discourse analysis (Polanyi 1985), linguistic content analysis (Roberts 1989; Roberts 1997), semantic text grammars (Franzosi 1990a; Franzosi 1995; Franzosi 1989; Franzosi 1990b), procedural task analysis (van Lehn and Garlick 1987), map analysis (Carley 1993), network analysis (Roberts and Popping 1996), proximity analysis (Danowski 1988), protocol analysis (Ericsson and Simon 1984). Each approach has its specific advantages which are related to a certain textual basis. No technique can be called the single most appropriate technique for all kinds of data.

Applying a formalized approach to cross-national text data means utilizing a structured process of converting the text-based string-variables into useful information. This can be achieved by "coding by hand" or the use of computers. In any case the goal is to "... allocate text features (characteristics) to variables by means of algorithms, that is, explicit, unambiguous logical or statistical operations" (Zuell et al. 1991).

The basis of text analysis, i.e. the text data or corpus, may consist of spoken texts, e.g. interviews, monologues or dialogues, advertisements, or it may consist of written texts, e.g. answers to a questionnaire, newspapers articles, letters, etc. or a combination of written and spoken text material (Melina 1998). The quality of text analysis depends heavily on the quality of the categorization scheme (Berelson 1952). There are two approaches for the development of a categorization scheme:

- development of relevant categories, based on the researcher's understanding of the context of the situation of interest. Portions of the text are coded with respect to this scheme 
which was developed based on a theoretical understanding of the underlying concept or construct (theory driven approach)

- the categorization scheme is constructed a posteriori, based on the content of the textual material which is analyzed. The attempt is to generate those categories from the available textual corpus, which are more relevant or significant for the analysis (data driven method).

Using multiple raters is useful for increasing the validity of the categorization scheme. After completion of this step the next task is the actual coding of the text data. Depending on the mode of analysis, coding can either be an intellectually challenging task or a manual task which might be done with computer-support (automated or semi-automated coding). After coding, a typical next step is the computer-assisted statistical analysis of the data. The amount of numerical values which are extracted from the textual data determines the further application of statistical procedures. Factor analysis, multidimensional scaling, cluster analysis or correspondence analysis are examples of multivariate methods that allow a reduction in the complexity of the data. It is thus possible to gain a better understanding of the underlying dimensions that are under investigation.

Using formalized procedures for the interpretation of textual data can be a promising complementary application of standard quantitative approaches. Especially when the comparison of data from various national and cultural backgrounds is at stake, the qualitative approach helps to broaden the view and deliver insights which cannot be gained by quantitative methods.

\section{RESEARCH DESIGN}

For the exploration of cross-national differences in materialism an exploratory study was undertaken. A questionnaire comprising qualitative and quantitative sections was designed to identify possible differences in the understanding of materialism, as operationalized by Richins and Dawson (1992). Based on the literature review outlined above, materialism was treated as a structural variable for purposes of comparing national cultures or "examining institutions within a culture of consumption" (Inglehart 1981). However, since the comparison of materialism scores across cultures is only feasible when the underlying construct serves the same function in all cultures under scrutiny, we explored the crossnational differences in materialism using alternative research strategies. Following the 'etic' school of thought, the materialism measure was used in 4 convenience subsamples from graduate university programs. The reliability of the measure was analyzed and first steps to validate the construct in different countries were undertaken. In order to grasp possible deficiencies in the "traditional" quantitative approach and to develop national differences in materialism, formalized qualitative analysis was subsequently used.

\subsection{Measure}

The 18-item materialism scale, as developed by Richins and Dawson (1992) was included in section II of the questionnaire. A German version of the scale was developed using backtranslation technique (Brislin 1970). Items were ordered randomly. This procedure was deemed to defuse the effect of similar response patterns with regard to the 3 dimensions of the materialism measure.

\subsection{Sampling}

A convenience sample of 169 participants was taken from the adult student population of four universities, located in different countries. Despite the well-known representativity problems 
encountered with convenience samples and those specific to student samples, efforts were made to neutralize usual biases by including only older students from graduate programs. In this way biases due to young age, limited financial resources and overall student lifestyle were limited.

The sample comprised 4 groups of students in graduate programs. 42 students were interviewed at the Wirtschaftsuniversitaet Wien in Austria, 33 students at University of Dortmund, Germany and two English-speaking groups of students were interviewed. 28 students who participated in an US-based MBA program at University of South Carolina, USA and 66 students who studied in a graduate marketing program at University of Tulsa, OK.

With regard to age, mean age was 26 years, with the two US-samples bringing the mean value up 3 years from around 23 years. Respondents in the sample had about 2 brothers and sisters and annual spending on foreign travel was around US-\$1,200 (ATS 13,000). The sample was predominantly male $(60.7 \%)$ and single (65.9\%). Only within the USC and Tulsa subsamples was the proportion of married people slightly higher. Most of the respondents were living in a city $(88.0 \%)$ and with regard to disposable income, the respondents considered themselves to dispose of an amount of money which was about average $(67.9 \%)$ or slightly above average (24.8\%). Travel and ownership data showed no peculiarities, with the European subsamples having traveled more often within Europe (especially the southern European countries) and the US-subgroups having more exposure to English-speaking territories (Australia, NorthAmerica).

Bivariate product-moment correlations were calculated for the materialism-scores ${ }^{2}$ of the two subgroups $^{3}$ and selected demographic variables. Surprisingly, this validity check did not result in any significant differences across the groups (see Table 2). This finding complemented our interpretation in the subsequent multivariate analysis.

Table 2: validation using demographic variables

\begin{tabular}{|l|c|c|}
\cline { 2 - 3 } \multicolumn{1}{c|}{ Correlations } & MATSCORE & MATSCORE \\
\multicolumn{1}{l|}{} & German subsample & US subsample \\
\hline VAC_ATS travel-spending & $-.092^{*}$ & -.094 \\
& $(.433 / 75)$ & $.367 / 94$ \\
\hline SIBLING brothers and sisters & .149 & -.084 \\
& $(.201 / 75)$ & $(.422 / 94)$ \\
\hline OWNSHIP ownership & .191 & .004 \\
& $(.100 / 75)$ & $(.972 / 94)$ \\
\hline
\end{tabular}

* Pearson Correlation, values in brackets represent sig.-level, 2-tailed and $N$

\section{RESULTS}

\subsection{Quantitative results}

As the first step the total sample of $\mathrm{N}=168$ was used for exploratory factor analysis which led to the exclusion of 8 reverse scored items out of the 18 original items developed by Richins and Dawson (1992), due to ambiguous loadings in the factor matrix. An exploratory factor analysis of the remaining 10 items suggested a scale with three moderately correlated factors

Materialism scores were calculated as summated rating scales, based on the analyses in the chapter below.

The sample was split into a German-speaking and English-speaking subgroup for reasons of comparing "national" differences. The rationale and justification for this procedure is outlined in the section below. 
(61\% cumulative variance explained), the structure of factor loadings being quite similar to the Richins and Dawson results, except for item MAT11 and MAT14. To show the relationships among scale items, Table 3 provides the pattern matrix from the principal component analysis (with varimax rotation) with data from the total sample. The first component corresponds to Richins and Dawsons "success" factor, the second concerns "happiness", which relates to the perception that possessions are needed for happiness and the third component represents the "centrality" of acquisitions and possessions generally.

Table 3: Exploratory factor analysis of materialism items (total sample)

\begin{tabular}{|l|c|c|c|}
\hline Rotated Component Matrix & \multicolumn{3}{|c|}{ Component } \\
\hline & 1 & 2 & 3 \\
\hline I like a lot of luxury in my life. (mat11) & .738 & & \\
\hline I admire people who own expensive homes, cars, and clothes. (mat13) & .667 & & \\
\hline $\begin{array}{l}\text { Some of the most important achievements in life include acquiring } \\
\text { material possessions. (mat14) }\end{array}$ & .458 & .560 & \\
\hline The things I own say a lot about how well I'm doing in life. (mat16) & .670 & & \\
\hline I like to own things that impress people. (mat17) & .708 & & \\
\hline My life would be better if I owned certain things I don't have. (mat02) & & .808 & \\
\hline I'd be happier if I could afford to buy more things. (mat04) & & .685 & \\
\hline $\begin{array}{l}\text { It sometimes bothers me quite a bit that I can't afford to buy all the } \\
\text { things I'd like. (mat05) }\end{array}$ & & .664 & \\
\hline I enjoy spending money on things that aren't practical. (mat09) & & & .838 \\
\hline Buying things gives me a lot of pleasure. (mat10) & & & .789 \\
\hline
\end{tabular}

Extraction Method: Principal Component Analysis. Rotation Method: Varimax with Kaiser Normalization. Rotation converged in 5 iterations. Only loadings greater than .35 are shown.

Due to sample size limitations and the exploratory character of this study we did not perform confirmatory analysis on the dataset. Instead, the sample was split into a German-speaking (Austrian and German students) and English-speaking subgroup (US-students from USC and Tulsa). The rationale for this aggregation was based on:

a) an exploratory data analysis, which did not show significant differences with respect to materialism (both for the English-speaking and the German-speaking groups) and

b) earlier research, indicating that Germany and Austria fall in the same country cluster, when plotted using 29 indicator variables (see Sethi 1971).

Furthermore, with respect to Hofstede's cultural dimensions of power distance and uncertainty avoidance (Hofstede 1980), Austria and Germany share the same properties of small power distance and strong uncertainty avoidance. In a more recent study Craig, Douglas and Grein (1992) developed a multidimensional map of European countries, which positioned Germany closely next to Austria with respect to two dimensions - cost of living and standard of living. These arguments added to the decision to group the samples based on language as a proxy variable for different nations.

However, when splitting the sample into a German-speaking (Austrian and German students) and English-speaking subgroup (US-students from USC and Tulsa) the factor-analysis resulted in a totally different materialism-structure. For the German-speaking subgroup of the sample a 3-component factor structure was identified (see Table 4). For the English-speaking subgroup a 2-component factor structure was found (see Table 5). Coefficient alpha was calculated separately for the items comprising the three and two factors. The alpha scores ranged from .70 to .7858 for the single scale in both subsamples. According to DeVellis this was a respectable value (DeVellis 1991), strengthening the factor-analysis results. 
Table 4: Rotated Component Matrix for German - subgroup

\begin{tabular}{|l|c|c|c|}
\hline Items & \multicolumn{3}{|c|}{ Component } \\
\hline & 1 & 2 & 3 \\
\hline My life would be better if I owned certain things I don't have. (mat02) & & & .861 \\
\hline I'd be happier if I could afford to buy more things. (mat04) & .676 & & \\
\hline $\begin{array}{l}\text { It sometimes bothers me quite a bit that I can't afford to buy all the } \\
\text { things I'd like. (mat05) }\end{array}$ & & .425 & .622 \\
\hline I enjoy spending money on things that aren't practical. (mat09) & & .819 & \\
\hline Buying things gives me a lot of pleasure. (mat10) & & .740 & \\
\hline I like a lot of luxury in my life. (mat11) & .770 & & \\
\hline I admire people who own expensive homes, cars, and clothes. (mat13) & .662 & & \\
\hline $\begin{array}{l}\text { Some of the most important achievements in life include acquiring } \\
\text { material possessions. (mat14) }\end{array}$ & .777 & & \\
\hline The things I own say a lot about how well I'm doing in life. (mat16) & .455 & & \\
\hline I like to own things that impress people. (mat17) & .730 & & \\
\hline $\begin{array}{l}\text { Extraction Method: Principal Component Analysis. Rotation Method: Varimax with Kaiser Normalization. Rotation } \\
\text { converged in 5 iterations. ger_sample, Only loadings greater than .35 are shown. }\end{array}$
\end{tabular}

Table 5: Rotated component matrix for English - subgroup

\begin{tabular}{|l|c|c|}
\hline Items & \multicolumn{2}{|c|}{ Component } \\
\hline & 1 & 2 \\
\hline My life would be better if I owned certain things I don't have. (mat02) & .780 & \\
\hline I'd be happier if I could afford to buy more things. (mat04) & .765 & \\
\hline $\begin{array}{l}\text { It sometimes bothers me quite a bit that I can't afford to buy all the things I'd } \\
\text { like. (mat05) }\end{array}$ & .516 & \\
\hline I enjoy spending money on things that aren't practical. (mat09) & & .856 \\
\hline Buying things gives me a lot of pleasure. (mat10) & & .808 \\
\hline I like a lot of luxury in my life. (mat11) & .632 & \\
\hline I admire people who own expensive homes, cars, and clothes. (mat13) & .686 & \\
\hline $\begin{array}{l}\text { Some of the most important achievements in life include acquiring material } \\
\text { possessions. (mat14) }\end{array}$ & .640 & \\
\hline The things I own say a lot about how well I'm doing in life. (mat16) & .554 & \\
\hline I like to own things that impress people. (mat17) & .549 & .473 \\
\hline
\end{tabular}

Extraction Method: Principal Component Analysis. Rotation Method: Varimax with Kaiser Normalization. Rotation converged in 3 iterations. eng_sample, Only loadings greater than .35 are shown.

Recent literature on equivalence issues in international marketing research and cross-national consumer research suggests additional procedures for testing for measurement invariance (Salzberger 1998; Salzberger et al. 1997; Steenkamp and Baumgartner 1998). However, confirmatory factor analysis using multiple groups was not applicable for the dataset. This implied that more rigorous tests for configural, metric and scalar invariance could not be performed (Salzberger et al. 1999; Sinkovics et al. 1998; Steenkamp and Baumgartner 1998). Although this methodological limitation might be overcome in the future by replicating the study using bigger samples, we think that for the exploratory scope of the study the results support our interpretation.

Overall, the exploratory factor analysis results suggested that the materialism construct served different functions in the countries. This lack of 'functional equivalence' (Douglas and Craig 1983) or 'construct inequivalence' (van de Vijver and Leung 1998) implied that we had to refrain from comparing the materialism scores. The materialism scale could not be used for cross-cultural comparisons because the internal structure of the measurement instrument was completely different in the two samples. Therefore, using the summated ratings of the scale 
for cross-national comparisons would lead to wrong and highly misleading results. Additionally, the results called for supplementary investigation as to why the materialism construct cannot be measured the same way cross-nationally and where the differences may come from.

\subsection{Qualitative approach and correspondence analysis}

The second step involved the use of a formalized text-analysis procedure. This was deemed to identify possible cultural differences which might account for the differences in the factor structures between the English and German speaking samples.

We used descriptive statements which respondents provided to the following open-ended question (included in section I of the questionnaire): "You are discussing the future and the goals which ought to be achieved with people close to you, your friends, etc. What would you respond in this case? What is it that really matters to you in your current life and in the future?" (free association). The inclusion of this question in the questionnaire served as a basis for enriching the original Richins and Dawson scale for international purposes. Furthermore it provided substantial material for exploring why obviously culture-bound concepts like materialism cannot be measured the same way cross-nationally and where national differences on materialism may come from.

Correspondence analysis was used as method of analysis. This method is very flexible in terms of data-requirements and the graphical display of output. However, it is rarely used in marketing contexts (Blasius and Rohlinger 1988). The subjects' answers to the statement mentioned above were categorized by three independent raters. First, each of them created his/her own categories. These categories were subsequently discussed within the group. Classification was sufficiently similar among the three raters. In a joint discussion and interpretation session 12 categories were established. All three raters agreed on this categorization. Afterwards the responses were assigned to the appropriate categories (binary data coding). Table 6 enumerates and describes the categories and their content.

Table 6: Categories and description

\begin{tabular}{|l|l|l|}
\hline$\#$ & Category (Label) & Description \\
\hline 1 & Success (Success) & General success, goals, achievement \\
\hline 2 & $\begin{array}{l}\text { Material aspects } \\
\text { (Money) }\end{array}$ & Standard of living, wealth, money, possessions \\
\hline 3 & $\begin{array}{l}\text { Social contexts } \\
\text { (Social) }\end{array}$ & Relationships, harmony, family harmony, kids, friends, partnership \\
\hline 4 & Job (Job) & Job success, company, respect for what is done \\
\hline 5 & Studying (Study) & Finish studies, success in studies, continuous learning \\
\hline 6 & $\begin{array}{l}\text { Self improvement } \\
\text { (Sel) }\end{array}$ & $\begin{array}{l}\text { Self improvement (active personality development), experiences } \\
\text { (passive personality development), flexibility, creativity }\end{array}$ \\
\hline 7 & Joy (Joy) & $\begin{array}{l}\text { Leisure time, travel, enjoyment, foreign cultures, adventure, } \\
\text { international context, sport, success in sporting activities }\end{array}$ \\
\hline 8 & Happiness (Happy) & Satisfaction, being happy, general happiness \\
\hline 9 & Empathy (Empathy) & $\begin{array}{l}\text { Social engagement, social activities, helping others, sharing with } \\
\text { others, contribution to society }\end{array}$ \\
\hline 10 & Religion (Religion) $)$ & Belief, morality, ethics \\
\hline 11 & Health (Health) & Physical health, fitness and healthy feeling \\
\hline 12 & Stability (Stable) & Stability of own reproduction, social security \\
\hline
\end{tabular}

The individual respondents' materialism-score served as a classification variable for the columns. The sample was not only split into an English-speaking subgroup and a German- 
speaking subgroup, but also divided into subgroups by level of materialism, according to the raw score in the shortened materialism-scale (Richins and Dawson 1992). Three groups were formed, differentiating between low materialism, medium materialism and highly materialistic persons.

For correspondence analysis canonical normalization was used to represent the relations between row- and column- variables graphically. For both the English-speaking subsample (principal inertia and the German-speaking subsample it was possible to represent the information in a two-dimensional grid without loss of information (cumulative proportion of variance explained by two dimensions $=1.00$ ).

For interpretation of the statistics 'explaining' and 'explained' points were determined for each quadrant and dimension. A point is called 'explained' if one axis contributes to that points variance by more than $50 \%$. In other words: if that points loading on one factor exceeds the explained variance limit of 0.5 (Jambu 1992). For explaining points the average is $(1 / 3)$ 0.33 for the column variables, and (1/12) 0.08 for the row-variables. Table 7 lists explaining points in both dimensions and both subsamples. A quick look shows us that both with the English-speaking-subsample as well as with the German-speaking-subsample 'success' plays a vital role. However, 'job' related matters and 'self-improvement' are far more important for the English subgroup than the German subgroup.

Table 7: Explaining points in both dimensions and subsamples

\begin{tabular}{|c|c|c|c|}
\hline \multicolumn{2}{|c|}{ Dimension 1} & \multicolumn{2}{|c|}{ Dimension 2} \\
\hline negative semi-axis & positive semi-axis & negative semi-axis & positive semi-axis \\
\hline \multicolumn{4}{|c|}{ English-speaking subsample } \\
\hline hi-mat & & low-mat & med-mat \\
\hline $\begin{array}{ll}\text { - } & \text { success } \\
\text { - job }\end{array}$ & $\begin{array}{ll}\text { - } & \text { material aspects } \\
\text { - } & \text { self improve } \\
\text { - } & \text { health } \\
\end{array}$ & $\begin{array}{ll}\text { - } & \text { empathy } \\
\text { - } & \text { stability } \\
\text { - } & \text { health } \\
\end{array}$ & $\begin{array}{ll}\text { - } & \text { success } \\
\text { - } & \text { self improve } \\
\text { - } & \text { religion } \\
\end{array}$ \\
\hline \multicolumn{4}{|c|}{ German-speaking subsample } \\
\hline hi-mat & low-mat & low-mat & med-mat \\
\hline $\begin{array}{ll}\text { - } & \text { success } \\
\text { - } & \text { studying } \\
\text { - } & \text { empathy }\end{array}$ & • joy & $\begin{array}{l}\text { - } \text { material aspects } \\
\text { - job } \\
\text { - } \text { happiness }\end{array}$ & - religion \\
\hline
\end{tabular}

Table 8 lists those points explained by the two dimensions included (whose portion of explained variance exceeds 50\%). This clearly shows that dimension one explains far more points than dimension two. Again, we see that there are certain differences between the English-speaking subsample and the German-speaking subsample. For instance 'material aspects' are configured along dimension one in the English subgroup, while only moderating medium materialism in the German subgroup. Furthermore low-materialism scores go hand in hand with 'stability', 'studying' and 'health' concerns in the English subgroup, while in the German subgroup they are related to (lack of) 'material' aspects and 'joy'.

Table 8: Points explained in both dimensions and subsamples

\begin{tabular}{|c|c|c|c|}
\hline \multicolumn{2}{|c|}{ Dimension 1} & \multicolumn{2}{|c|}{ Dimension 2} \\
\hline negative semi-axis & positive semi-axis & negative semi-axis & positive semi-axis \\
\hline \multicolumn{4}{|c|}{ English-speaking subsample } \\
\hline hi-mat & & low-mat & med-mat \\
\hline $\begin{array}{ll}\text { - } & \text { success } \\
\text { - } & \text { social context }\end{array}$ & $\begin{array}{l}\text { - material aspects } \\
\text { - } \\
\text { studying }\end{array}$ & - empathy & $\begin{array}{ll}\text { - } & \text { joy } \\
\text { - } & \text { religion }\end{array}$ \\
\hline
\end{tabular}




\begin{tabular}{|c|c|c|c|}
\hline $\begin{array}{ll}\text { - } & \text { job } \\
\text { - } & \text { happiness }\end{array}$ & $\begin{array}{ll}\text { - } & \text { self improve } \\
\text { - } & \text { health }\end{array}$ & & \\
\hline \multicolumn{4}{|c|}{ German-speaking subsample } \\
\hline hi-mat & low-mat & & med-mat \\
\hline $\begin{array}{ll}\text { - } & \text { success } \\
\text { - } & \text { studying } \\
\text { - } & \text { empathy }\end{array}$ & $\begin{array}{ll}\text { - } & \text { self improve } \\
\text { - } & \text { joy } \\
\text { - } & \text { health } \\
\text { - } & \text { stability }\end{array}$ & $\begin{array}{l}\text { - } \text { material aspects } \\
\text { - job } \\
\text { - } \text { happiness }\end{array}$ & $\begin{array}{ll}\text { - } & \text { religion } \\
\text { - } & \text { social context }\end{array}$ \\
\hline
\end{tabular}

The graphical results are shown in Figure 2 for the English-speaking subsample and Figure 3 for the German-speaking subsample. For both subsamples, row and column elements are represented in a joint plot.

Figure 2: Graphical correspondence results - English-speaking subsample

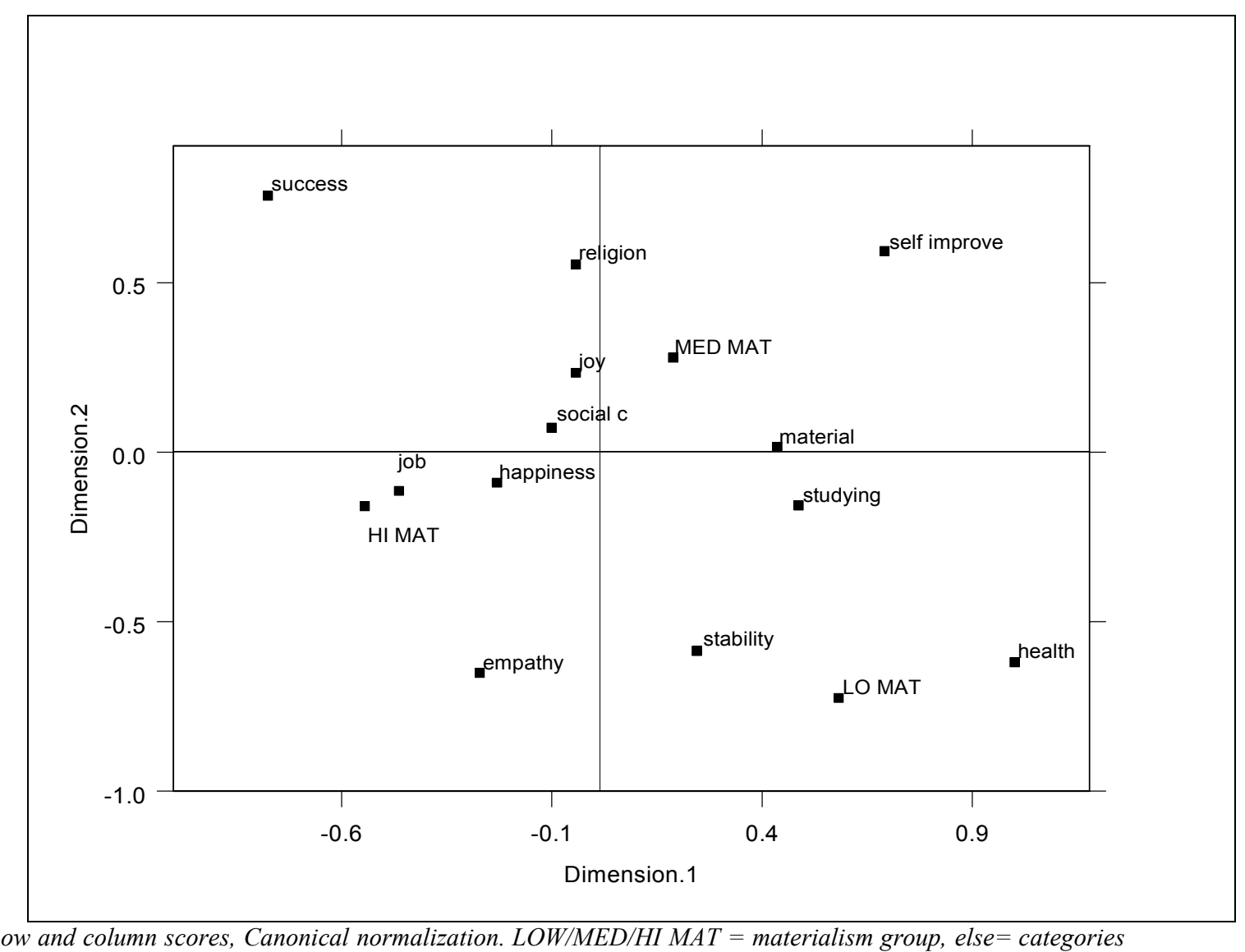

The results of the correspondence analysis provide us with qualitative pieces of information and graphical representations of different materialism patterns. This contributes to a more comprehensive understanding of the materialism construct across the different groups (English-speaking subgroup and German-speaking subgroup). As outlined above, the configuration of explaining and explained points in the English-subsample differs significantly from the configuration in the German-subsample. Thus, looking at the configural differences in the graphical grid we manage to qualitatively interpret and comprehend the differences reported in the quantitative 'factor analysis' study above. Therefore the correspondence results help to understand where the different factor analysis results stem from. 
Figure 3: Graphical correspondence results - German speaking subsample

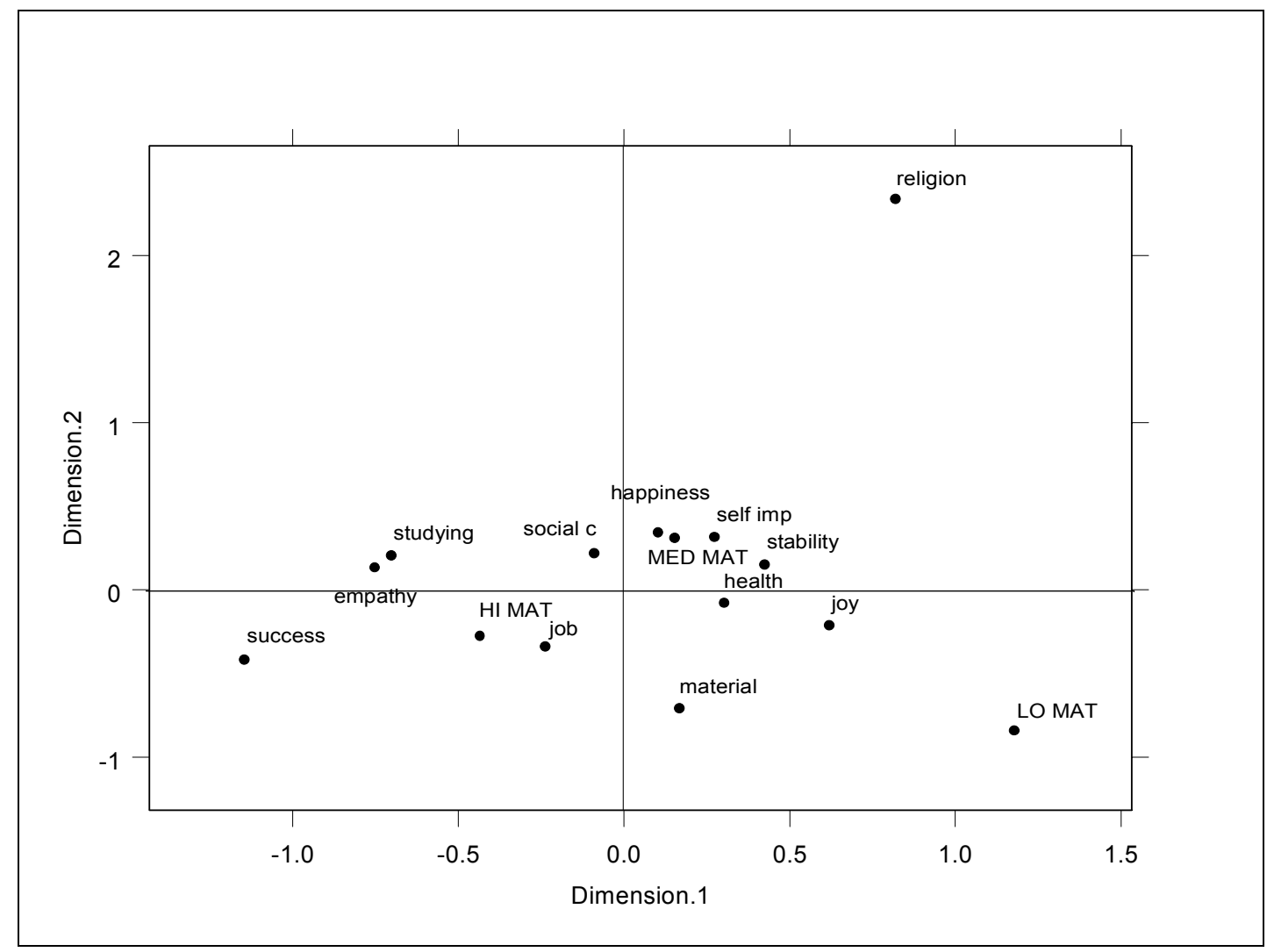

Row and column scores, Canonical normalization. LOW/MED/HI MAT = materialism group, else = categories

Table 7 and Table 8 served as a helpful guiding tool for the interpretation of the differences between the English-speaking and the German-speaking subsample. The interpretation of explaining points was complemented by the explained points in Table 8 . The fundamental differences between English-speaking and German-speaking subsamples with regard to their comprehension of 'materialism' was mirrored by the configuration of explained points in the joint space.

Generally, for the English-subgroup there was a clear differentiation between hi-materialism scores and low-materialism scores. Highly 'materialistic' aspects were configured along dimension 1, such as 'success' and 'job', whereas for the German-speaking subsample the differentiation between job and leisure-related aspects was somewhat more blurry. The data for the English-speaking subsample represented those facets typically linked to the term 'materialism' much more clearly. Job-matters and personal success as determinants of personal/individual success demonstrated the conceptual difference between 'materialism' in the English and German-subgroup. Looking at dimension 2, medium and low-materialism scores, the conceptual difference of materialism across both subsamples could also be seen very clearly. While for the English-speaking subsample 'empathy', 'stability' and 'health' statements are configured near 'low-materialism', for the German-speaking subsample 'material aspects', 'job' and 'happiness' are close to the 'low-materialism' group. This could be interpreted as a fundamentally different understanding of extra-materialistic aspects. While for the English-speaking subsample there is a association between job-matters, success and personal development, low-materialistic people from the German-speaking subsample indicated a more comprehensive understanding of happiness. For them, happiness was related to a subsistence-level of reproduction, indicative of a somewhat more 'collectivistic' type of orientation. 


\subsection{Comparison of the quantitative and the qualitative findings}

Following the exploratory factor analysis results left us with the somewhat unsatisfactory conclusion that there was a lack of comparability of the datasets. The analysis resulted in a three-dimensional solution for the German-subgroup while the English-subgroup only revealed a two-dimensional solution. Considering the exploratory type of the analysis the factorial differences did only provide for some tentative hypotheses as to where these might stem from. 'Only money matters' seemed to capture the results for the English-subgroup, with enjoyment or pleasure being less important. For the German-subgroup the enjoyment dimension was more differentiated and items representing "acquisition as the pursuit of happiness" could be factored together.

With differences in the factorial structure emerging from the analysis, questions were raised as to where these factorial differences in materialism might stem from. Following the research strategy outlined in chapter 2.2 above, we combined the quantitative approach by employing a qualitative method. Correspondence analysis served as an exploratory tool and means of idea generating in this context. Using statements from consumers regarding the open question "... What is it that really matters to you in your current life and in the future?" and plotting the categorized statements along high and low materialism scores helped to unveil explanations for the differences in the factor analysis results. For the English-subgroup, job-matters and personal success was strongly related to high-materialism. For the German-subgroup, extramaterialistic aspects (e.g. empathy or stability) played a much higher role.

From a methodological perspective the combination of quantitative and qualitative strategies was complimentary, i.e. both analyses were given equal weight and data collection conducted simultaneously. Performing correspondence analysis helped us to explore findings which we were unable to identify by factor analysis alone. In this sense, rather than trying to compare or evaluate the two methodological approaches in terms of which one was more or less appropriate for cross-national research, we explored national differences in the domain of the construct. We feel comfortable that this approach may prove valuable for future research.

\section{CONCLUSION AND IMPLICATIONS FOR FUTURE RESEARCH}

\subsection{Consequences of findings for materialism research}

There is a trend towards using more and more rigorous and refined statistical methods of measurement in order to check for cross-national comparison of data (Salzberger 1998; Steenkamp and Baumgartner 1998). However, the fundamental problem of comparing incomparable pieces of information from diverse national and cultural backgrounds sometimes hampers these endeavors (Sinkovics et al. 1998). The duality of either going for an etic- or an emic-type of research approach seems to be a fundamental obstacle for valid research results in cross-national research, especially when using psychographic scales and transferring them from one nation to another nation in order to apply them in real-world marketing situations (e.g. segmentation and targeting decisions using consumer data). There is obviously a persistent danger in using an etic approach when conceptional differences suggest an emic approach or - alternatively - using an emic approach, when an etic approach would be possible (thus ignoring rich qualitative information).

From a methodological point of view, our findings call for the use of 'alternative research strategies' to overcome the emic - etic duality in cross-national research. By applying formalized qualitative steps of data coding and interpretation on well-defined research problems (see Figure 1), we managed to extract information which helped us to understand why obviously 'culture-bound' concepts like 'materialism' could not be measured in the same 
way. By graphically representing the mindset of respondents, we were able to explore the reasons for the conceptual differences. While this 'alternative research strategies' approach does not necessarily make the 'incomparable' comparable, it helps us to find out the reasons for incomparability.

\subsection{Limitations and outlook}

As indicated in the body of the paper the present study served an exploratory function. The majority of articles up to this date focused on various aspects of materialism and the relationship between materialism and other psychographic measures. Only a limited amount of effort has been devoted to the measurement of materialism across national boundaries. This study, tries to deal with the aforementioned limitations. However, sample size limitations only allow for a limited generalizability of our findings. From a methodological perspective, the sample size limitation restricted the research to the use of exploratory factor analysis and rendered impossible the application of confirmatory analysis and confirmatory factor analysis across multiple groups.

Potential paths for enhancement of this type of research comprise the usage of bigger datasets. This means that the sampling framework should be extended to cover bigger sample sizes, and not only student-samples. On the quantitative side of analysis this would make it possible to test for configural, metric and also scalar invariance using confirmatory factor analysis with multiple groups, as suggested by Steenkamp and Baumgartner (1998). Furthermore bigger datasets and a computer-based categorization of responses to open questions may provide more comprehensive empirical foundations for explaining conceptual differences. This may enhance our understanding of why transferability-conflicts occur.

\section{REFERENCES}

Belk, Russell W. (1985), "Materialism: Trait Aspects of Living in the Material World," Journal of Consumer Research, 12 (3), 265-80.

---- (1984), "Three Scales to Measure Constructs Related to Materialism: Reliability, Validity, and Relationships to Measures of Happiness," Advances in Consumer Research, 11, 291-97.

Bengston, Vern L. and Mary Christine Lovejoy (1973), "Values, Personality, and Social Structure," American Behavioral Scientist, 16 (July/August), 880-912.

Berelson, B. (1952), Content analysis in communication research. Clencoe Ill.: Free Press.

Blasius, J. and H. Rohlinger (1988), "Korrespondenzanalyse - Ein multivariates Verfahren zur Auswertung von zweidimensionalen Kontingenztabellen," in Fortschritte der StatistikSoftware 1, 4. Konferenz über die wissenschaftliche Anwendung von StatistikSoftware, F. Faulbaum and H.-M. Uehlinger, Eds. Stuttgart, New York: Fischer.

Brannen, Julia (1992), "Combining qualitative and quantitative approaches: an overview," in Mixing Methods: Qualitative und Quantitative Research, Julia Brannen, Ed. Aldershot, UK: Avebury Ashgate Publishing Limited.

Bredemeier, Harry C. and Jackson Toby (1960), Social Problems in America: Costs and Casualties in an Acquisitive Society. New York: Wiley.

Brislin, R.W. (1970), "Back Translation for Cross-Cultural Research," Journal of CrossCultural Psycholgoy, 1 (3), 185-216. 
Bryman, Alan (1992), "Quantitative and qualitative research: further reflections on their integration," in Mixing Methods: qualitative and quantitative research, Julia Brannen, Ed. Aldershot: Avebury Ashgate Publishing Limited.

---- (1988), Quantity and quality in social research. London ; Boston: Unwin Hyman.

Burdsal, Charles Jr. (1975), "An Examination of Second Order Motivational Factors as Found in Adults," Journal of Genetic Psychology, 127 (September), 83-89.

Campbell, Donald T. (1969), "Various Social Attitude Scales," in Measures of Political Attitudes, John P. Robinson and Phillip R. Shaver, Eds. Ann Arbor, MI: Survey Research Center, University of Michigan.

Carley, K. (1993), "Coding choices for textual analysis: a comparison of content analysis and map analysis," Sociological Methodology, 23, 75-126.

Churchill, G.A. (1979), "A Paradigm for Developing Better Measures of Marketing Constructs," Journal of Marketing Research, 16 (February), 64-73.

Claxton, Reid P., Jeff B. Murray, and Janda Swinder (1995), "Spouses' Materialism: Effects of Parenthood Status, Personality Type, and Sex," Journal of Consumer Policy, 18, 267-91.

Craig, C. Samuel, Susan P. Douglas, and Andreas Grein (1992), "Patterns of convergence and divergence among industrialized nations: 1960-1988," Journal of International Business Studies, 23 (4), 773-87.

Csikszentmihalyi, Mihaly and Eugene Rochberg-Halton (1981), The Meaning of Things: Domestic Symbols and the Self. Cambridge: Cambridge University Press.

Cushman, Philip (1990), "Why the Self Is Empty," American Psychologist, 45 (May), 599611.

Danowski, J.A. (1988), "Organizational Infographics and automated auditing: Using computers to unobtrusively gather and analyze communication," in Handbook of organizational communication, G. Goldhaber and G. Barnett, Eds. Norwood N.J.: Ablex.

Denzin, Norman K. (1970), The Research Act in Sociology. London: Butterworth.

DeVellis, R.F. (1991), Scale Development - Theory and Applications. Neybury Park: Sage.

DeYoung, Raymond (1985), "Encouraging Environmentally Appropriate Behavior: The Role of Intrinsic Motivation," Journal of Environmental Systems, 15 (4), 281-92.

Dickins, Dorothy and Virginia Ferguson (1957), "Practices and Attitudes of Rural white Children and Parents concerning Money," Missisippi Agricultural Experiment Station Technical Bulletin, 43.

Dittmar, Helga and Lucy Pepper (1994), "To have is to be: Materialism and person perception in working-class and middle-class British adolescents," Journal of Economic Psychology, 15 (2), 233-52.

Douglas, Susan P. and Samuel C. Craig (1983), International Marketing Research. Englewood Cliffs, NJ: Prentice-Hall Inc.

Eastman, Jacqueline K., Bill Fredenberger, David Campbell, and Stephen Calvert (1997), "The relationship between status consumption and materialism: A cross-cultural comparison of Chinese, Mexican and American students," Journal of Marketing Theory and Practice, 5 (1), 52-66. 
Elder, J.W. (1976), "Comparative Cross-national Methodology," Annual Review of Sociology, 2, 209-30.

Ellis, F.S. (1968), A lexical concordance to the poetical works of Percy Bysshe Shelley. New York: B. Franklin.

Ericsson, K.A. and H.A. Simon (1984), Protocol Analysis: Verbal reports as data. Cambridge: MIT Press.

Feldman, L.P. (1971), "Societal Adaptation: A New Challenge for Marketing," Journal of Marketing, 35, 54-60.

Fox, Richard Wightman and T.J.Jackson Lears (1983), The Culture of Consumption: Critical Essays in American History, 1880-1980. New York: Pantheon.

Franzosi, R. (1990a), "Computer-assisted coding of textual data," Sociological Methods and Research, 19, 225-57.

---- (1995), "Computer-assisted content analysis of newspapers: Can we make an expensive tool more efficient?," Quality and Quantity, 29, 157-72.

---- (1989), "From words to numbers: A generalized linguistics-based coding procedure for collecting textual data," Sociological Methodology, 19, 263-98.

---- (1990b), "Strategies for the prevention, detection, and correction of measurement error in data collected from textual sources," Sociological Methods and Research, 18, 442-72.

Früh, W. (1991), Inhaltsanalyse. Theorie und Praxis. München: Ölschläger Verlag.

Ger, Guliz and Russell W. Belk (1996), "Cross-cultural differences in materialism," Journal of Economic Psychology, 17 (1), 55-78.

Heilbroner, Robert L. (1956), The Quest for Wealth: A Study of Acquisitive Man. New York: Simon \& Schuster.

Heslin, Richard, Blair T. Johnson, and Brian F. Blake (1989), "Saver-Spender Scales," in Proceedings of the Society for Consumer Psychology 1988, David W. Schumann (Ed.). Washington, DC: Society for Consumer Psychology.

Hofstede, Geerd (1980), Culture's Consequences: International Differences in Work-Related Values. Beverley Hills: Sage Publications.

Inglehart, Ronald (1981), "Post-materialism in an Environment of Insecurity," American Political Science Review, 75, 880-900.

Jackson, Douglas N., A. Ahmed Sadrudin, and Nelson A. Heapy (1976), "Is Achievement a Unitary Construct?," Journal of Research in Personality, 10 (March), 1-21.

Jambu, M. (1992), Explorative Datenanalyse. Stuttgart, Jena, New York.

Justice, Blair and Roger Birkman (1972), "An Effort to Distinguish the Violent from the Nonviolent," Southern Medical Journal, 65 (6), 703-06.

Kelle, U. Ed. (1995), Computer-aided qualitative data analysis, methods and practice. London: Sage.

Kwon, Jung, Jochen Wirtz, Soo Jiuan Tan, and Ah Keng Kau (1999), "The seven faces of Singaporeans: A typology of Singapore consumers and their aspirations and life satisfaction," Asia Pacific Journal of Management, 16 (2), 229-48.

La Barbera, Priscilla A. and Gurhan Zeynep (1997), "The role of materialism, religiosity, and demographics in subjective well-being," Psychology and Marketing, 14 (1), 71-97. 
Lundstrom, William J. and Steven D. White (1999), "Intergerational and cultural differences in materialism: An empirical investigation of consumers from France and the USA," Journal of Euro-Marketing, 7 (2), 47-65.

Mallery (1985), "Universality and Individuality: The interaction of noun phrase determiners in copular clauses," in 23rd Annual Meeting of the Association for Computational Linguistics. Chicago.

Mannion, Caolan and Teresa Brannick (1995), "Materialism and its measurement," Irish Business and Administrative Research, 16 (1), 1-14.

Melina, Alexa (1998), "Computer-assisted text analysis methodology in the social sciences,". Mannheim: Zentrum für Umfragen, Methoden und Analysen (ZUMA ).

Miles, Matthew B. and Michael A. Huberman (1997), Qualitative data analysis : an expanded sourcebook (2. ed. ed.). Thousand Oaks CA: Sage Publications.

Moschis, George P. and Gilbert A. Churchill (1978), "Consumer Socialization: A Theoretical and Empirical Analysis," Journal of Marketing Research, 15 (November), 599-609.

Mukerji, Chandra (1983), From graven images : patterns of modern materialism. New York: Columbia University Press.

Muncy, James A. and Jacqueline K. Eastman (1998), "Materialism and Consumer Ethics: An exploratory Study," Journal of Business Ethics, 17, 137-45.

Nunnally, Num C. (1978), Psychometric Theory. New York: McGraw-Hill.

Pike, K. (1966), Language in Relation to a Unified Theory of the Structure of Human Behavior. NL: The Hague.

Polanyi, K. (1985), Telling the American story: A structural and cultural analysis of conversational storytelling. Norwood N.J.: Ablex.

Rassuli, Kathleen M. and Stanley C. Hollander (1986), "Desire -- Induced, Innate, Insatiable?," Journal of Macromarketing, 6 (2), 4-24.

Richins, Marsha L. (1987), "Media, Materialism, and Human Happiness," in Advances in Consumer Research, Melanie Wallendorf and Paul Anderson, Eds. Vol. 14. Provo, UT: Association for Consumer Research.

---- (1994), "Special Possessions and the Expression of Material Values," Journal of Consumer Research, 21 (December), 522-33.

Richins, Marsha L. and Scott Dawson (1992), "A Consumer Values Orientation for Materialism and Its Measurement: Scale Development and Validation," Journal of Consumer Research, 19 (December), 303-16.

Richins, Marsha L. and Floyd W. Rudmin (1994), "Materialism and economic psychology," Journal of Economic Psychology, 15 (2), 217-32.

Roberts, C.W. (1989), "Other than counting words: a linguistic approach to content analysis," Social Forces, 68, 147-77.

---- (1997), "Semantic text analysis: On the structure of linguistic ambiguity in ordinary discourse," in Text analysis for the social sciences: methods for drawing statistical inferences from texts and transcripts, C.W. Roberts, Ed. Mahwah N.J.: Lawrence Erlbaum Assoc. Publishers. 
Roberts, C.W. and R. Popping (1996), "Themes, syntax and other necessary steps in the network analysis of texts: a research paper," Social Science Information, 35 (4), 657 65.

Sacks, H. (1972), "On the analysability of stories by children," in Directions in Sociolinguistics, J. Gumprez and D. Hymes, Eds. New York: Rinehart \& Winston.

Salzberger, T., R. Sinkovics, and H.H. Holzmüller (1997), "Problems of Equivalence in Cross-Cultural Marketing Research," in Annual Conference of the Academy of Marketing Science, E.J.; Wilson and J.F. Hair (Eds.) Vol. XX. Coral Gables, Florida.

Salzberger, Thomas (1998), "Die Lösung von Äquivalenzproblemen in der interkulturellen Marketingforschung mittels Methoden der probabilistischen Meßtheorie," Doctoral Dissertation, Wirtschaftsuniversität Wien (WU-Wien).

Salzberger, Thomas, Rudolf Sinkovics, and Bodo B. Schlegelmilch (1999), "Data Equivalence in Cross-Cultural Research: A Comparison of Classical Test Theory and Latent Trait Theory Based Approaches," Australasian Marketing Journal, 7 (2), 2338.

Scott, Cliff and William J. Lundstrom (1990), "Dimensions of possession satisfaction: A preliminary analysis," Journal of Consumer Satisfaction/Dissatisfaction and Consumer Behavior, 3, 100-04.

Sethi, Prakash S. (1971), "Comparative Cluster Analysis for World Markets," Journal of Marketing Research, 8 (3), 348-54.

Sinkovics, Rudolf R., Thomas Salzberger, and Hartmut H. Holzmüller (1998), "Assessing Measurement Equivalence in Cross-National Consumer Behavior Research: Principles, Relevance and Application Issues," in New Developments and Approaches in Consumer Behaviour Research, Ingo Balderjahn and Claudia Mennicken, Eds. London: MacMillan.

Steenkamp, J.B. and H. Baumgartner (1998), "Assessing Measurement Invariance in CrossNational Consumer Research," Journal of Consumer Research, 25 (June), 78-90.

van de Vijver, Fons and Kwok Leung (1998), Methods and data analysis for cross-cultural research. Thousand Oaks, CA: Sage Publications.

van Lehn, K. and S. Garlick (1987), "Cirrus: An automated protocol analysis tool," in 4th International Workshop on Machine Learning, P. Langley (Ed.). Los Altos CA: Morgan-Kaufman.

Wackman, Daniel B., Greg Reale, and Scott Ward (1972), "Racial Differences in Responses to Advertising among Adolescents," in Television in Day-to-Day Life, Eli A. Rubenstein and George A. Comstock and John P. Murray, Eds. Rockville, MD: U.S. Department of Health, Education and Welfare.

Ward, Scott and Daniel Wackman (1971), "Family and Media Influences on Adolescent Consumer Learning," American Behavioral Scientist, 14 (January/February), 415-27.

Weber, R. (1990), Basic content analysis (2nd Edition ed.). Newsberry Park, CA: Sage Publications.

Weitzman, Eben A. and Matthew B. Miles (1995), Computer Programs for Qualitative Analysis. Thousand Oaks: Sage Publications.

Wold, H. (1980), "Model Construction and Evaluation when Theoretical Knowledge is Scarce," in Evaluation of Econometric Models, J. Kmenta and J.B. Ramsey, Eds. New York. 
---- (1982), "Soft Modeling: The Basic Design and some Extensions," in Systems under Indirect Observations, H.G. Jöreskog and H. Wold, Eds. Vol. Part 2. Amsterdam.

Zinkhan, George M. (1994), "Advertising, materialism, and the quality of life," Journal of Advertising, 23 (2), 1-4.

Zuell, C., P.P. Mohler, and A. Gleis (1991), Computerunterstützte Inhaltsanalyse mit TEXTPACK PC. Stuttgart: Gustav Fischer Verlag. 